\title{
The Use of Telemedicine in Bangladesh during COVID-19 Pandemic
}

\author{
Mohammad Monirujjaman Khan, S. M. Tahsinur Rahman, Sabik Tawsif AnjumIslam \\ Department of Electrical and Computer Engineering, North South University, Dhaka, Bangladesh \\ Email: monirujjaman.khan@northsouth.edu,smtahsinur@gmail.com, sabik.tawsif@northsouth.edu
}

How to cite this paper: Khan, M.M., Rahman, S.M.T. and AnjumIslam, S.T. (2021) The Use of Telemedicine in Bangladesh during COVID-19 Pandemic. E-Health Telecommunication Systems and Networks, 10, $1-19$.

https://doi.org/10.4236/etsn.2021.101001

Received: November 30, 2020

Accepted: February 26, 2021

Published: March 1, 2021

Copyright $\odot 2021$ by author(s) and Scientific Research Publishing Inc. This work is licensed under the Creative Commons Attribution International License (CC BY 4.0).

http://creativecommons.org/licenses/by/4.0/

\section{(c) (i) Open Access}

\begin{abstract}
This paper presents the impact of telemedicine use among patients and healthcare professionals during the epidemic due to COVID-19 outbreak in Bangladesh. According to our findings, as the coronavirus outbreak quickly surges worldwide, many countries are adapting non-therapeutic preventative measures. Telemedicine is the exchange of medical information from one location to another using electronic communication. Telemedicine refers to the use of information and communication technology to provide healthcare support. During the pandemic, it is safer not to visit a hospital physically for consultation until and unless it is of utmost emergency. In this scenario, Telemedicine plays a vast role in developing both the quality and access to healthcare services during a pandemic. The current (COVID-19) scenario has shown us the significance of using Telehealth to deliver healthcare, especially as a means of decreasing the risk of cross-contamination caused by close contact. Bangladesh, like every other nation, has started using telemedicine as a means of providing digital healthcare services. As the outbreak continues, this paper finds that several telemedicine service providers in Bangladesh have increased their operation for serving the general mass. This paper finds the role of telemedicine during the COVID-19 pandemic as a bridge between providing safe healthcare consultation while keeping social distance as advised. The current situation of COVID-19 in Bangladesh has also been discussed in this paper. Despite some challenges of a telemedicine application in Bangladesh, the role of telemedicine is quite impactful during the pandemic.
\end{abstract}

\section{Keywords}

Telehealth, Telemedicine, Pandemic, Sustainability, Outbreak, Coronavirus, COVID-19, Remote Monitoring

\section{Introduction}

With the outbreak of novel coronavirus- 2 which is declared as a pandemic and 
an international public health emergency by the World Health Organization (WHO) [1], the entire world is working to prevent it. It is a quickly evolving and emerging circumstance. In less than 5 months after the initial emergence of the virus in December 2019, about two million people in 185 countries around the world have been identified as confirmed cases of coronavirus disease 2019. Researchers around the globe are working very hard to understand better the biology of $n \mathrm{CoV}-2$ and the epidemiology of the novel coronavirus disease-19. The calculated basic procreative number of viruses are informatively higher than many other contagious diseases, and eventually this results in the magnitude of health issues and facilities becoming engulfed, even in many countries which have the most advanced healthcare technology. A calculated $22 \%$ of cases lead to the crucial and complicated conditions. With some infrequent cases of critical illness in teenage individuals, people less than 62 years of age and with co-diseased conditions constitute one of the most unfortified groups.

There is yet no antiviral drug or vaccine has been approved for this kind of disease, and so, non-curative interventions to minimize the outspread of the uncommon virus are the most impressive act to control that disease. Globally, billions of people of all ages are staying at home to less the dissemination of the virus. Moreover, so many countries are taking preventive steps. Since Bangladesh is a middle-income country and it has densely populated areas, it is struggling to fight against the outspread of the disease. Consumed by fear, now so many doctors and physician are reluctant to provide the health service directly. For preventing the outburst of the COVID-19, the government and administration have already imposed restrictions and rules. Restrictions and limitations on the movement of the common people and declaring March 26 to April 4 as the public holiday is basically a direction for everyone to stay in their home. The incapability to consult with doctors physically, at such a moment, has emerged as one of the critical obstacles for the medical assistants who seek patients. So now the need for "Telemedicine" is vitally important more than ever.

Governments and administrations are preparing for the worst and devastating situation, quickly realizing the deadly impact of COVID-19 on health issues and global economy. Amidst the reports regarding the outspread of the virus, there's also identification (again) that Telehealth can play a vital role in the universal response. Obviously, Telehealth is the most reliable source for the dealing with communicable diseases. "Social distancing" [2] is the key factor which can decrease the transmission of this virus. And its decreasing person-to-person contact as well. The patients who tested positive for COVID-19, or those concerned about being infected, Telehealth can easily help them with an appropriate assessment by providing care and nursing through media [3]. People who are not infected with the COVID-19 virus, specially who are at higher risk of being affected (e.g. adults with preexisting health issues and medical complexity), Telehealth can provide them an appropriate access to the routine care without being at risk of unveiling in an overcrowded hospital. Anyway, if we want Telehealth to be fruitful for us during the current situation COVID-19 pandemic and for 
future disasters, firstly we have to ensure that this media is properly integrated into our health policy and is dealing as a "business as usual" modal quality. The motive of this article is to track the key requirements for ensuring that the importance of Telehealth is fully recognized, not only in emergencies (such as pandemics and disasters) but also in day to day life it is practiced.

Previously journals have been published regarding telemedicine and e-health [4]. Those journals have explained how Telehealth can be useful in this pandemic and how it can play a significant role in this crisis. It also addressed how the adoptions by patients and healthcare professionals have limited the use of telemedicine. Another journal discussed how telemedicine Western China's success could be used as a role model for other parts of the world [5]. A journal on telemedicine in Bangladesh and barriers in Bangladesh and how to overcome it [6] addressed the issues very accurately. But it did not give any solution on the currently available applications. This paper will try to solve that issue by portraying presently available solutions and how they can be used accurately. We will also showcase the present startups that are working on Telehealth and what unique ways they are trying to solve the issue that we are facing in COVID-19 Pandemic in Bangladesh.

\subsection{What Is Telemedicine?}

Telemedicine is the conveyance of medical services and the trading of medical care data across separations. The prefix "tele" gets from the Greek for "a good way off"; thus, more basically, telemedicine is medication a way off [7]. All things considered, it incorporates the entire scope of clinical exercises including determination, treatment and counteraction of sickness, proceeding with training of medical care suppliers and purchasers, and examination and assessment [8]. Telecare is a connected term and alludes to the arrangement, a way off, of nursing and network backing to a patient. Essentially, Telehealth alludes to general wellbeing administrations conveyed a good way off, to individuals who are not really unwell, yet who wish to stay well and autonomous.

\subsection{Working Procedure of Telemedicine}

Utilizing telemedicine administrations is extremely simple [9]. Generally, the administration utilizes an online record or a complementary telephone number. Patients demand a visit, submitting fundamental information on their condition, and afterward the doctor acknowledges the issue and schedule a time for the visit [10]. Telemedicine is a great innovation, but some things are needed to be ensured while applying this. Prior to utilizing it, surveying the patient's necessities and ensuring it's a fitting chance to utilize the innovation is a must [11]. Figure 1 shows classification system for telemedicine episodes. An example of Telemedicine system has been presented in Figure 2.

\subsection{Role of Telemedicine in Bangladesh}

Bangladesh is a country with $63.3 \%$ of its population living in the rural areas 


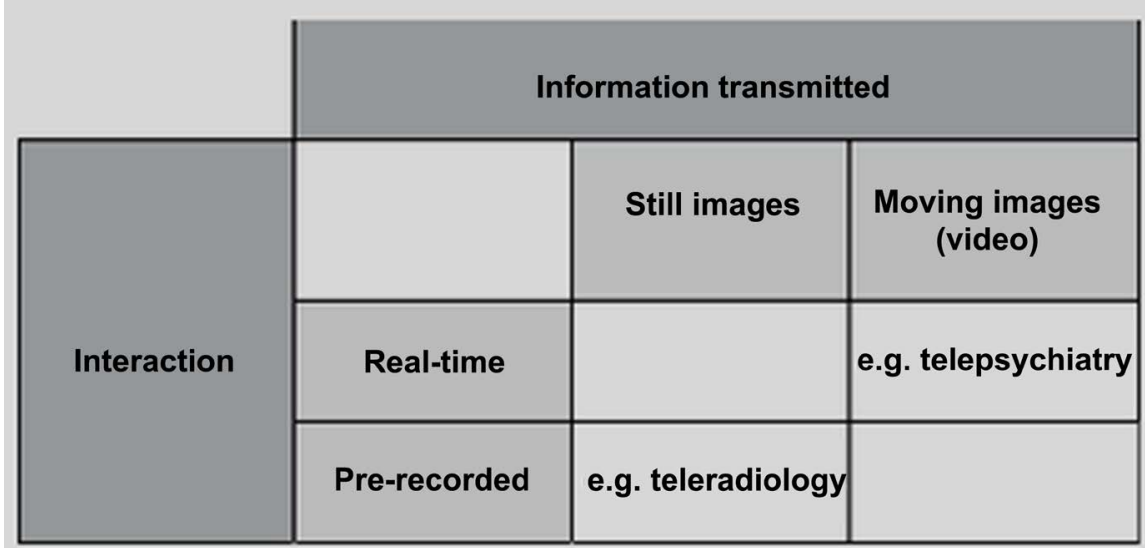

Figure 1. Classification system for telemedicine episodes.

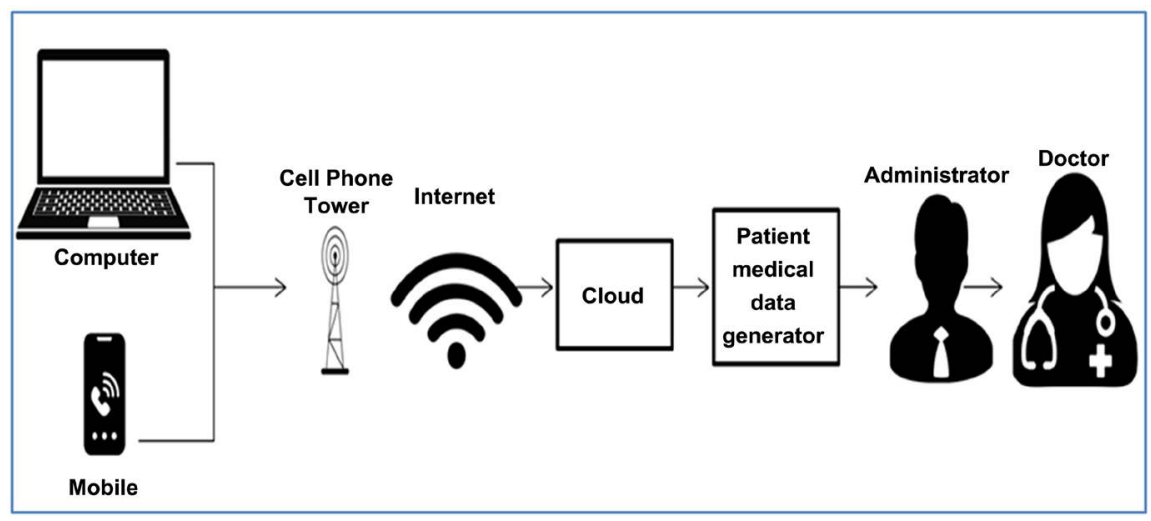

Figure 2. An example of telemedicine system architecture.

(according to data provided by World Bank). And, among this population, it has around only 6 doctors per 100,000 citizens, which is very low. The situation is very unassuming as in most of the cases, doctors from cities have to travel to village for long hours amidst traffic and it is a very common scenario where it is seen that a patient in need is not getting a proper consultation or medical solution on time. With this huge gap in availability of healthcare professionals and proper medical facilities in the rural area, telemedicine can play a big role. With the increase amount of telemedicine in these rural areas, a lot of the problems can be solved within a spur of minutes [12]. Figure 3 shows the graph of rural population (\% of total Population) in Bangladesh.

\subsection{Companies with Functional Telemedicine in Bangladesh}

In 2005, Grameen Telecom (GTC) in participation with the Diabetic Association of Bangladesh (DAB) dispatched telemedicine administrations, giving patients at Faridpur General Hospital access to specialist doctors of their decision in Dhaka [13]. After that, many companies came and started providing Telemedicine facilities in Bangladesh. Sebaghar, Tonic by Grameenphone, Pulse Healthcare, DaktarBhai, e-Hospital Ltd. Dhaka University Telemedicine Program etc. are some of the companies and programs. So how do these companies work? They 


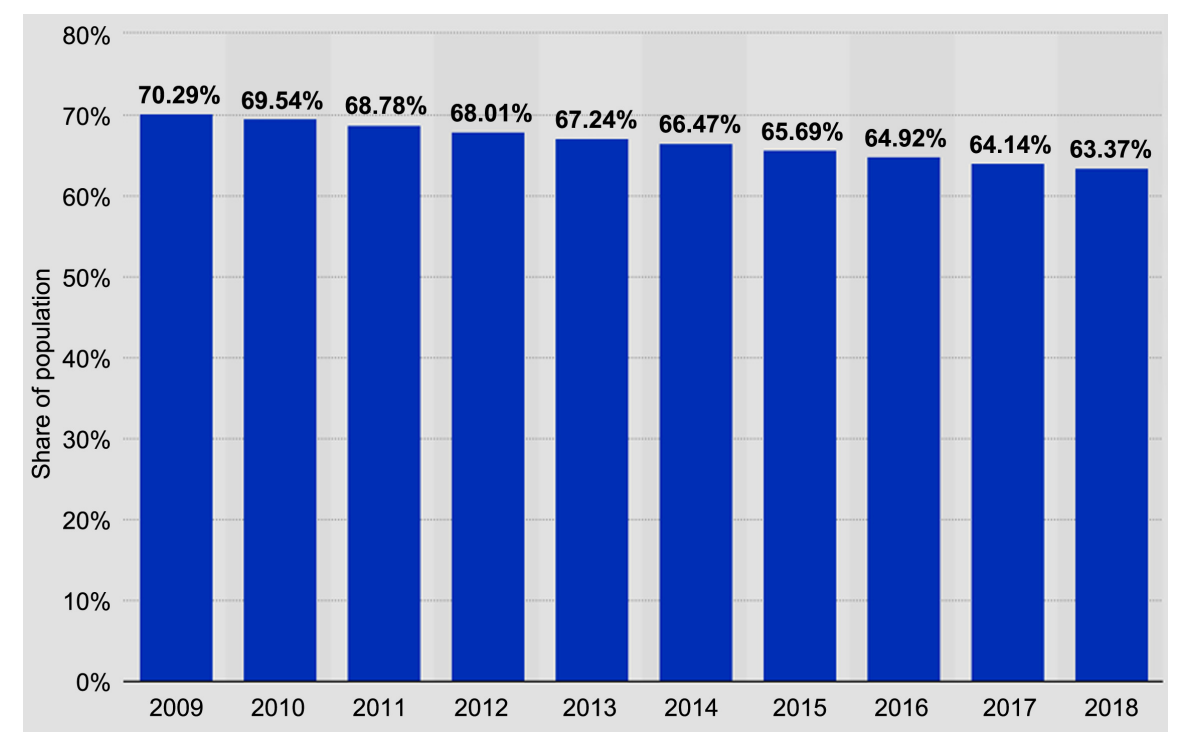

Figure 3. Rural population (\% of total Population)-Bangladesh.

provide facilities where a patient can schedule an appointment with a doctor via Video call through the homegrown online platform developed by these companies. Apart from the video call consultation services, they provide services like e-PHR, home pathology and so on.

\section{Pulse Health Services Limited}

Pulse Health services Limited offers a cloud-based smart health monitoring system bundled with health insurance. They conduct periodic health check-ups (e.g. body temperature, BMI, blood pressure, blood sugar, oxygen saturation) using smart devices, and keep the data saved in a cloud platform that can be accessed through a mobile application under personal profiles [14]. Figure 4 shows Pulse Health Application Features.

\section{Jeeon}

Jeeon Connect is the first online platform for retail drug specialists and chemists in Bangladesh. At present they have affiliation with 2084 pharmacies all around Bangladesh. Their versatile mobile application for pharmacies considers digital short listing of required items, value estimations, and passing orders to their individual organization's deals and circulation MIS. Orders can be prepared with or without web.

For pharmacies, this guarantees item accessibility, paying little mind to the recurrence of deals calls. For pharmaceutical companies, this can expand market presence, can cost successfully catch the interest from beforehand low ROI drug stores, and improves usage of dispersion tasks. Due to Jeeon's presence in the market, sourcing pharmaceutical aids in the middle of pandemic has made lives easier for people [15]. Figure 5 shows services provided by Jeeon Connect. Figure 6 presents services provided by Sebaghar App.

\section{Sebaghar}

Sebaghar is a telemedicine and video consulting service platform of Bdtask Limited, a Bangladeshi software and IT company. Sebaghar is a public medium 


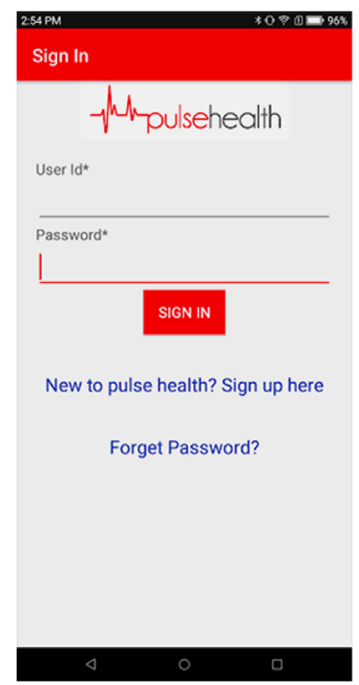

Home Screen

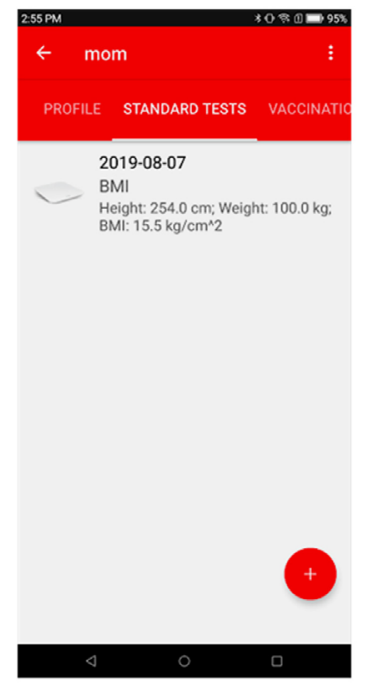

Stabdard test

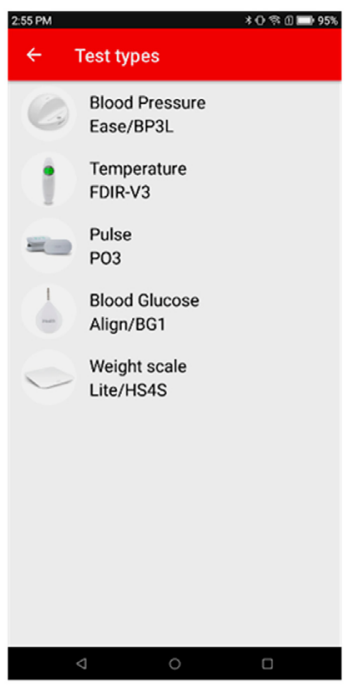

Test types

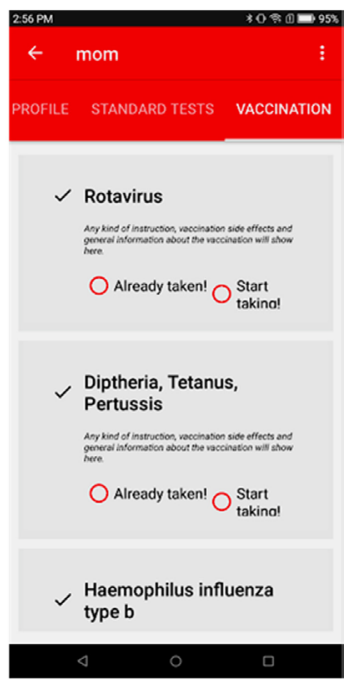

Vaccination record

Figure 4. Pulse health application features.

\section{Key Features}

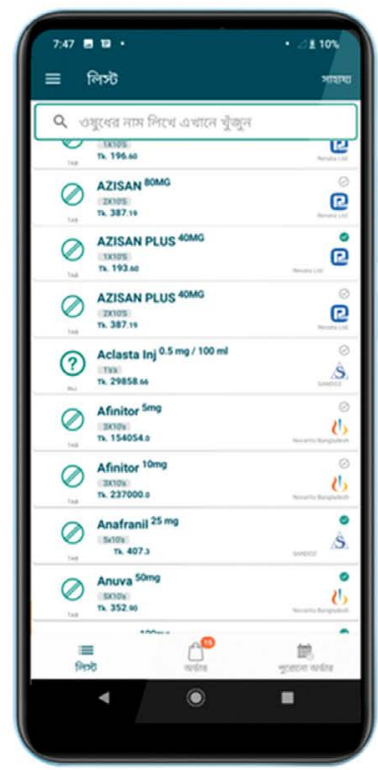

Single list of products across multiple companies with SMART SEARCH functionality
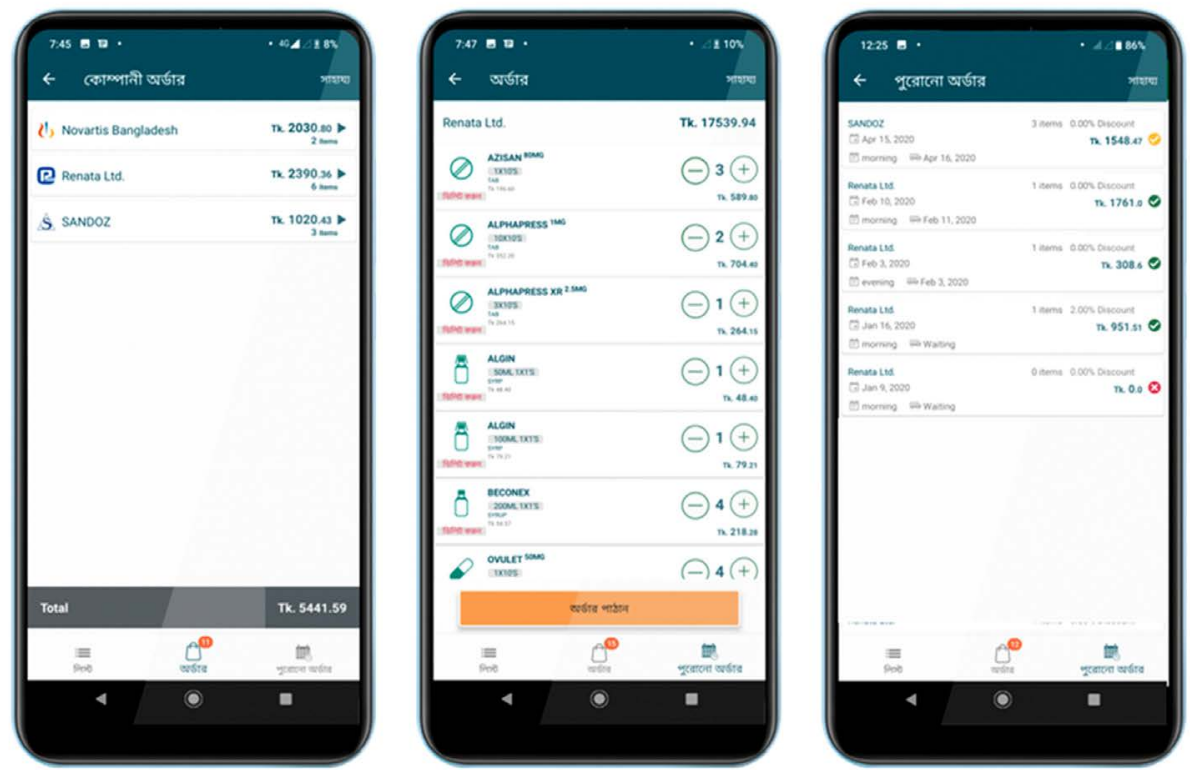

Produdt SHORTLISTS summarised by company.
Easy editing and single click ordering
Comprehensive transaction history, updated in real time

Figure 5. Services provided by Jeeon Connect.

where Sebaghar connects the service recipient (patient) and the service provider (doctor).

Significant services of Sebaghar are divided into two parts, one is patient-centric, and the other is doctor-centric. The patient-centric services are telemedicine, video counselling, e-prescription, medicine reminder and service health blog. All 

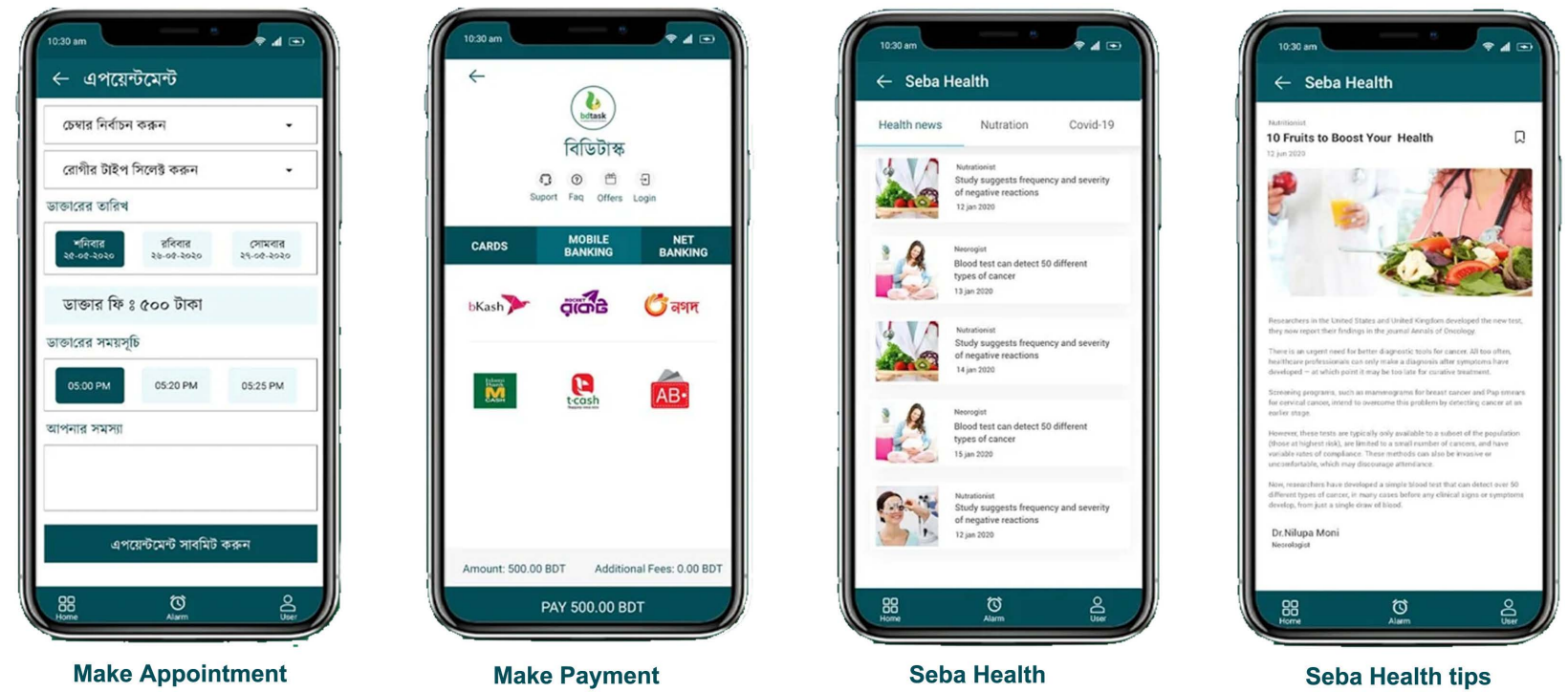

Figure 6. Services provided by Sebaghar App.

services are readily available through Sebaghar app. Besides, the doctor-centric services are online chambers, online scheduling, online e-prescription, and doctor online profile creation. Services provided by Sebaghar has eased life for mass people during the ongoing pandemic [16].

\section{Bachao-Health}

Bachao-Health is a Facebook Messenger based telemedicine service. It is automatic chatbot service that provides medical consultation via the messenger app. Anyone can have access to their services. The language of instruction of this service is Bengali. So, majority of the people of Bangladesh can easily access and enjoy the services offered by Bachao-Health. The app has a predefined set of instructions that helps a patient/user take consultation via selecting from a range of options [17]. Figure 7 shows the Home page of Bachao-Health.

\section{Tonic}

Tonic is the first health based digital offering service application in Bangladesh, providing variety of services. They focus on primary health care through phone and provide digital health related needs. Their motive is to provide Universal Health Coverage (UHC) to all the people in Bangladesh. Tonic app is based on monthly subscription package. It includes Health Tips which provides health tips to the customers, Tonic Doctor which provides primary medical queries via phone, Tonic Discounts which provides discounts to its members at over 800 hospitals and Tonic Cash which provides cash coverage up to 250,000 Tk per subscription year. All these services are provided in Tonic mobile app and website [18]. Figure 8 shows the services provided by Tonic and user interface.

\section{The Current COVID-19 Scenario in Bangladesh}

The novel COVID has extended across more than 210 nations and their areas. In 


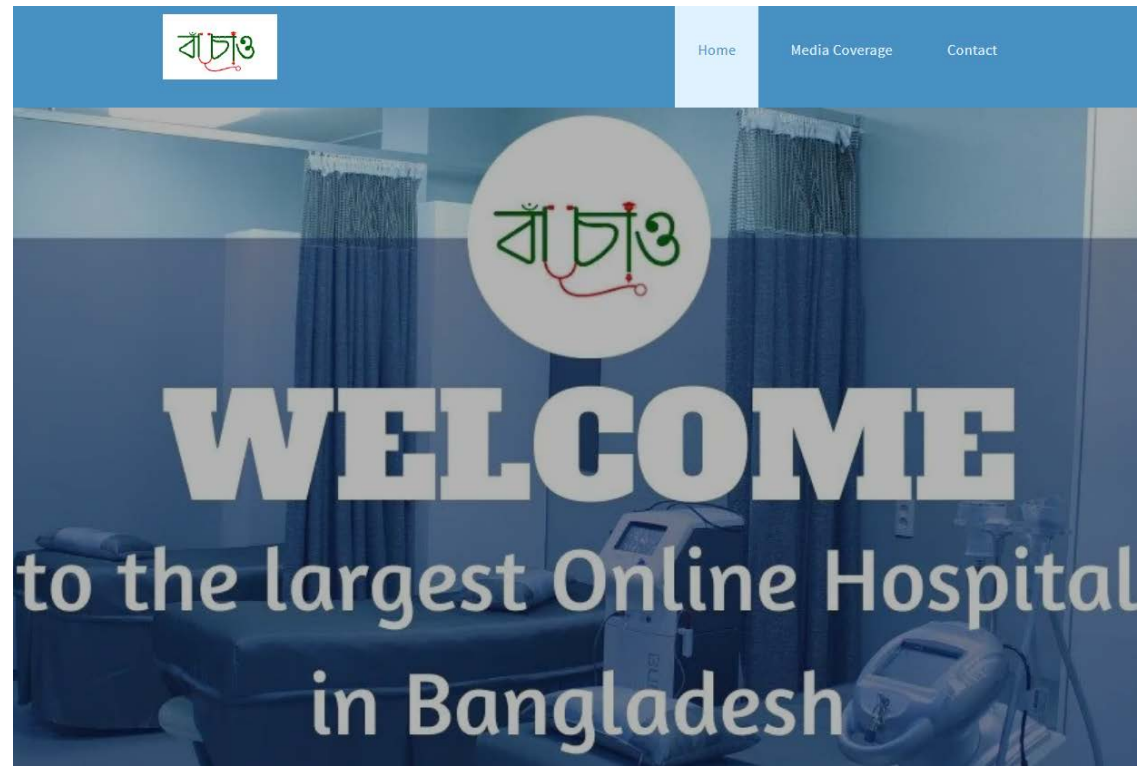

Figure 7. Home page of Bachao-Health.

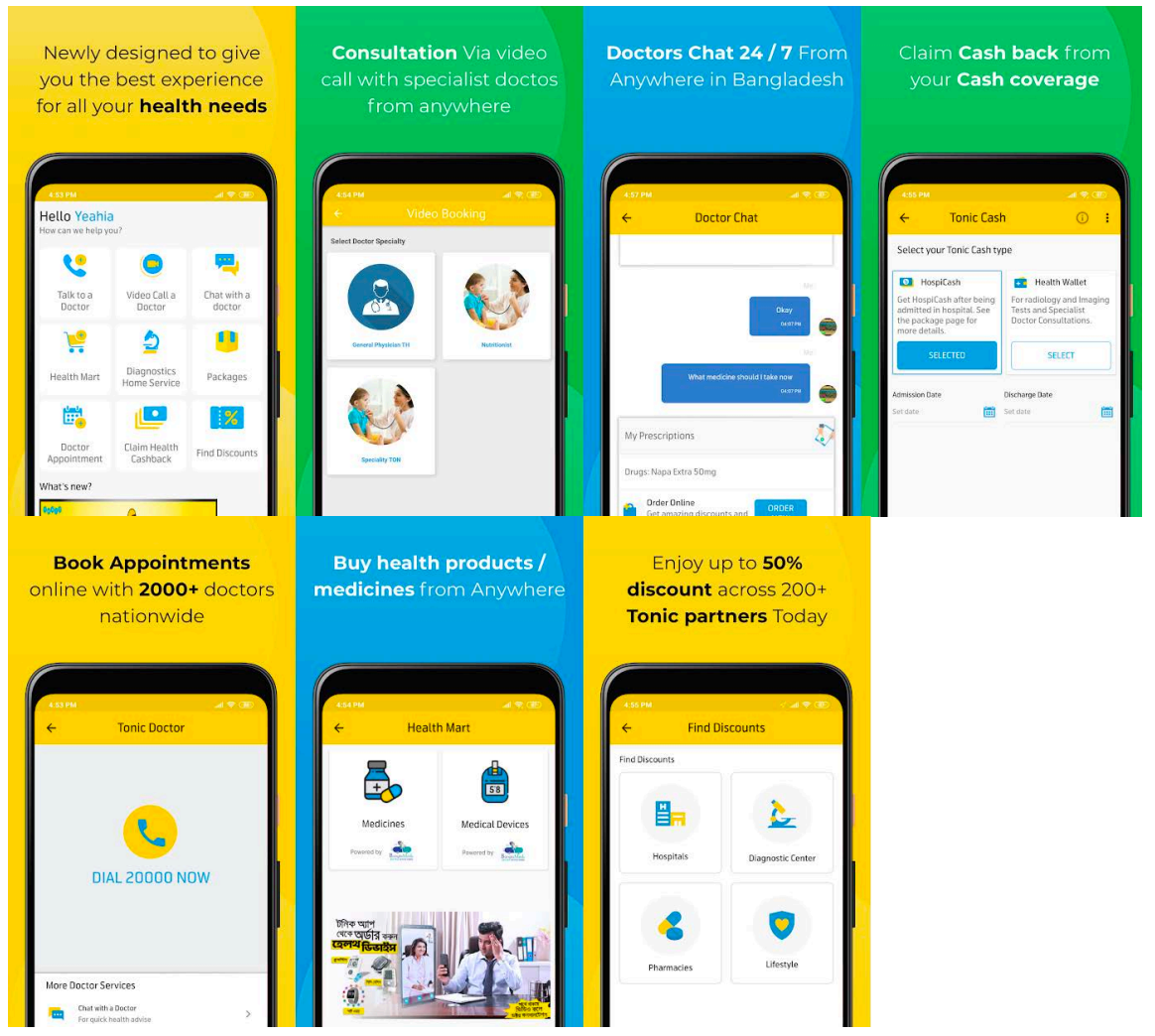

Figure 8. Services provided by tonic and user interface.

Bangladesh first, coronavirus cases were found on 08 March. For the security of the entire populace, the public authority reported "lockdown" all through the whole nation from 23 March to 30 May and prepared by making some vital strides for bringing issues to light among its kin to keep them safe and get the infection far from them. Between 8 March and 23 November 2020, as indicated 
by the DGHS Press Release <https://corona.gov.bd/press-release $>$ there were four hundred forty-nine thousand seven hundred sixty (449,760) COVID-19 cases affirmed by rRT-PCR, including six thousand four hundred and sixteen (6416) related deaths (CFR 1.43\%) [19]. Bangladesh is the top 24th nation on the planet and records for $0.8 \%$ of the COVID- 19 cases on the earth. In the epidemiological week 46, the number of new cases in Bangladesh was 12,095; case per 100,000 populaces for every week is 7.1. New death cases amounted to 127; deaths per 100,000 every week is 0.07 . Week by week, new tests are 98,592 ; tests per million every week is 57.9 ; week by week test positivity is 12.3 . Starting at 16 November 2020, among the announced cases, $26.1 \%$ cases were affirmed in individuals somewhere between the range of 31 and 40 years of age, 19.3\%-in the age range of 21 to $30,18.8 \%-41$ to 50 years and $15.6 \%$ in the range of 51 and 60 years of age. The most noteworthy death rate $(31.5 \%)$ was accounted for in the age gathering of 61 to 70 years of age, $29.0 \%$ in the more established age gathering of 71 or more and $22.5 \%$ in the age bunch somewhere in the range of 51 and 60 years. Male spoke to $72 \%$ and $77 \%$ of the complete detailed affirmed COVID-19 cases and deaths separately (Figure $9 \&$ Figure 10).

Bangladesh took place among the fastest in the globe to arrive 2000 cases, reaching the number in just 40 days after its first case on March 8. Worldwide, only Italy reached this number faster [20] (Figure 11).

The situation is getting worse with COVID-19: Too many frontline workers and common people are testing positive every day. One instance of such a situation is the present DGHS main point and Upazila Health and Family Planning Officer, in one of the Bangladesh's COVID-19 hotspots. The day when that doctor tested positive for COVID-19, that day he was on duty on a 17-hour shift, and continued taking care to his patients over the telephone while staying in isolation. After

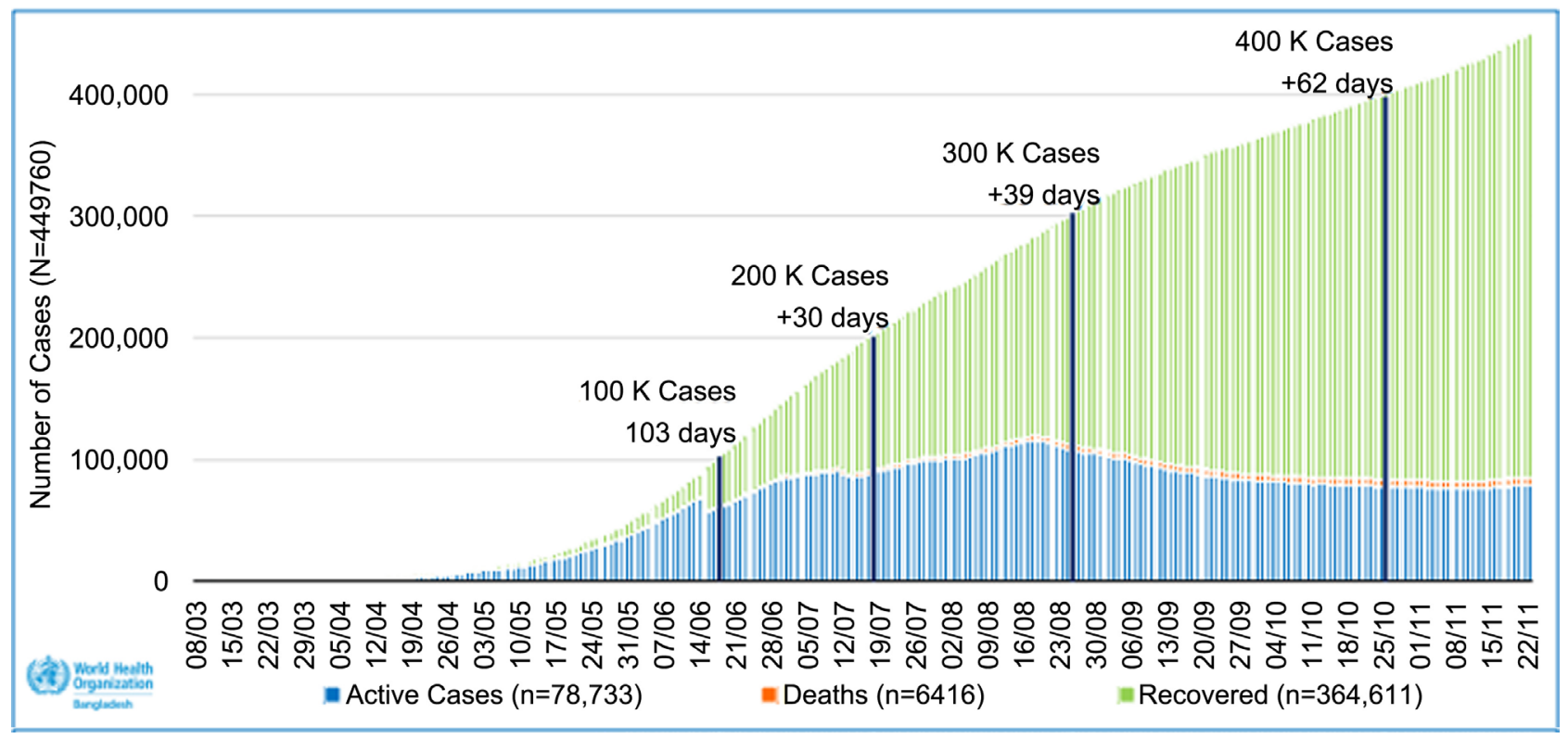

Figure 9. The figure above is showing trend of COVID-19 cases by Outcome, 08 March-23 November 2020, Bangladesh. 


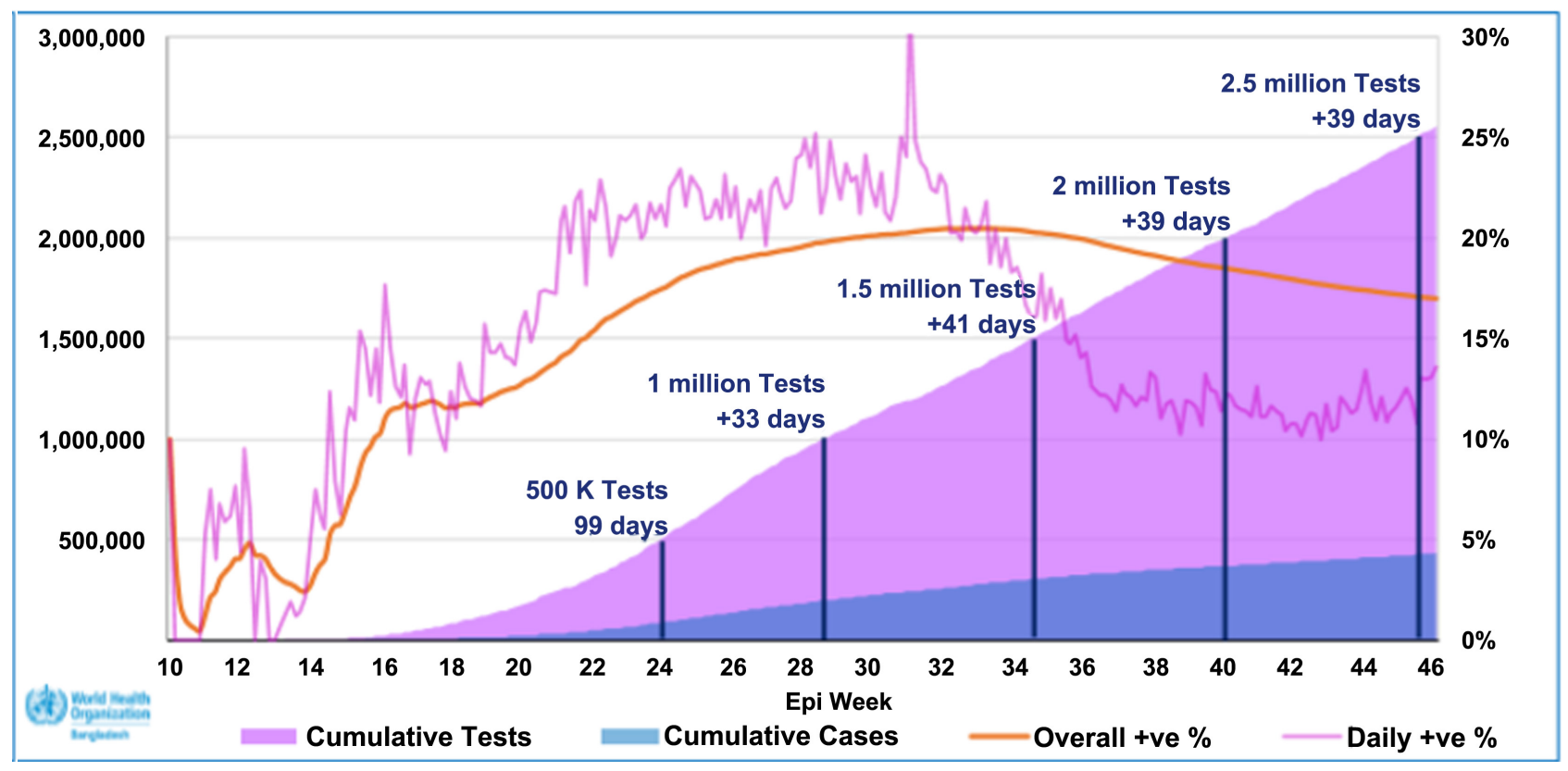

Figure 10. The graph above shows the cumulative number of samples tested and positivity rate, 08 March-16 November 2020 , Bangladesh.

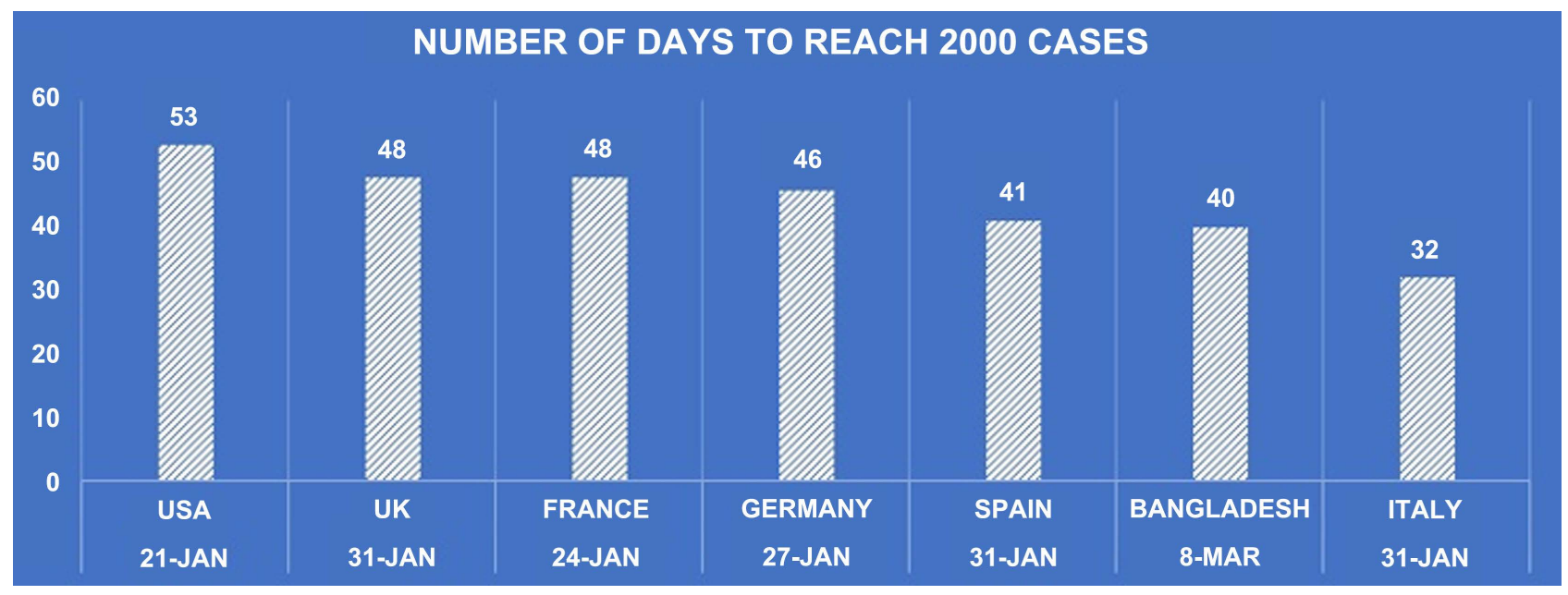

Figure 11. Number of days to reach 2000 cases in selected countries.

having recovered recently, he coordinates a six doctor's team and supervises treatment plans for about 900 patients. The team at first collects detailed medical information and all records to sort out between hospital admission and home quarantine for those patients. The doctor's opinion is that the sample testing stage is past by Bangladesh, and that anyone with certain symptoms of novel Coronavirus should be treated immediately as a COVID-19 patient and asked to stay home. As an alleviation measure for this virus, the doctor recommended separating groups divided by area just because they can easily call for help by dialing a single different number for getting medical advice. He called for sending the ambulances for critical patients in order to no one needs for going out in the open environment. 
Overall, there's a perfusing sense of belief among common people. News reports show raising infection risks in medical sectors, with so many frontline workers and common people are falling sick. In Dhaka's Mitford Hospital, 42 medical staff, including 23 doctors, tested positive with novel Corona virus in April 2020, allegedly from one patient who hid his details about being affected by the virus. Data shows from Bangladesh Doctors Foundation (BDF), general wards and intensive care units of as many as 12 hospitals and medicals across the country was closed down when the doctors and nurses were infected [21].

Since numerous emergency clinics and clinical focuses are shutting down, patients who are tested negative are being dismissed for standard test and required treatment, accordingly bothering their condition. A few clinics which capacity are likewise reluctant for taking in patients since they fear that they may be tainted with this infection, a mishap happened to a youthful Bangladeshi young lady who got back from Canada, passed on because of gastrointestinal complications when the specialists were reluctant to give her the treatment simply expecting that she was sullied with COVID-19, particularly since she had come from abroad.

Numerous emergency clinics have been designated explicitly for COVID-19 and to that zone, this pandemic has swarmed out assistance for non-Coronavirus patients, in Bangladesh where the clinical framework was at that point under tremendous issue even before this pandemic occurred. Since numerous specialists and clinical colleagues are avoiding the lab and clinics, observing required clinical gears, for example, ventilators and oxygen cylinder and veils have become a gigantic sort of issue, then again, influencing patients are experiencing non-Coronavirus with respect to diseases. For the fear of drawing near to the infection, patients who don't have COVID-19 are likewise hesitant not to go to the hospitals for past arrangements.

One young lady, gave interview for the article, she guaranteed that she went for a regular test to a private emergency clinic in March of this current year and in spite of the fact that in the clinic there were covers and hand sanitizers at their office, she saw most patients were reluctant to take prudent steps, in the wake of seeing this situation the woman chose not to get to hospital for her pre-scheduled appointment. As another option, she leans towards the telemedicine care benefits now at whatever point she needs any counsel with respect to her medical problems. This lockdown has expanded the weight of countless patients like this lady, who presently stress over having treatment on schedule and overseeing for transport.

\section{The Method of Telemedicine in Bangladesh}

The World Health Organization (WHO) has stated, "the conveyance of healthcare system, while distance is a censorious factor, by all healthcare specialists using statistics and information technologies for exchanging of information for the treatment of diagnosis and safety from injuries and fatal diseases, investigation and evaluation and for considering the knowledge of healthcare donors, all 
for the interest of developing the health of everyone and their communities". The plan was to conduct the healthcare to common people of remote corner, isolated places. Five entrepreneur's team developed one platform with digital technology for making it happen-at the same time when the technology allows high-rise outreach at a lower price. In February 2020, healthcare help centers appeared to be an uncontested way to restrain the outspread of COVID-19. And Doctor Dekhao got the dispensation from the ICT ministry in company with many others. And now, 20 similar telemedicine service donors are recorded by the health ministry on corona.gov.bd. They supply healthcare services in different capacities: round-the-clock, some for free too, while there's other services who charge money from the patients.

In any country, telemedicine has never been such popular media. But now perhaps it's the best alternative for the doctors for providing healthcare and also for the patients to get their virtual treatment. Anyway, the socio-economic materiality and the raising incapable healthcare service makes persuasive case for telemedicine.

A pregnant woman who was living at a remote village very far away from town centers in Gaibandha, would panic over the baby for not moving in her womb for a certain period, and her trip to the closest hospital can be tiring during odd hours, for instance, a call to the doctor in need can save her money, time and energy if she has nothing to be tensed about. If she is suggested to have medical assistance without delay, she can be saved. This pandemic made the children, pregnant women and old patients more unprotected. Now they are a greater of those requesting virtual visits.

In typical Bangladeshi pot, a patient, doesn't matter whether he has COVID-19 or not, chooses from where to get medical treatment and from which person. Having no idea about the remedy, that patient goes to the door of various doctors. By doing so, he at last may run out of budget money and end up having no required healthcare. Since March, it's estimated that through the platform about a thousand phone calls were made in every month on an average. Experts also believe, telemedicine can never replace the conventional in-person visits, instead it can help for reshaping the health services for the better.

The working procedure of Telemedicine differs from organization to organizations a lot. Government funded telemedicine projects handle telemedicine in a different way compared private funded telemedicine startups. The following Figure 12 shows the working procedure of the first ever telemedicine project of Bangladesh initiated by Center for Rehabilitation of Paralyzed (CRP) [22].

Medinova hospital has been offering medical consultancy via functional Telemedicine services in Bangladesh from 2006 to till now. Figure 13 shows the flowchart of telemedicine service developed by Medinova hospital [23].

From the analysis of different working procedures and methods of telemedicine, used in different time and by various organizations, this paper finds clear variations in usage of telemedicine. 


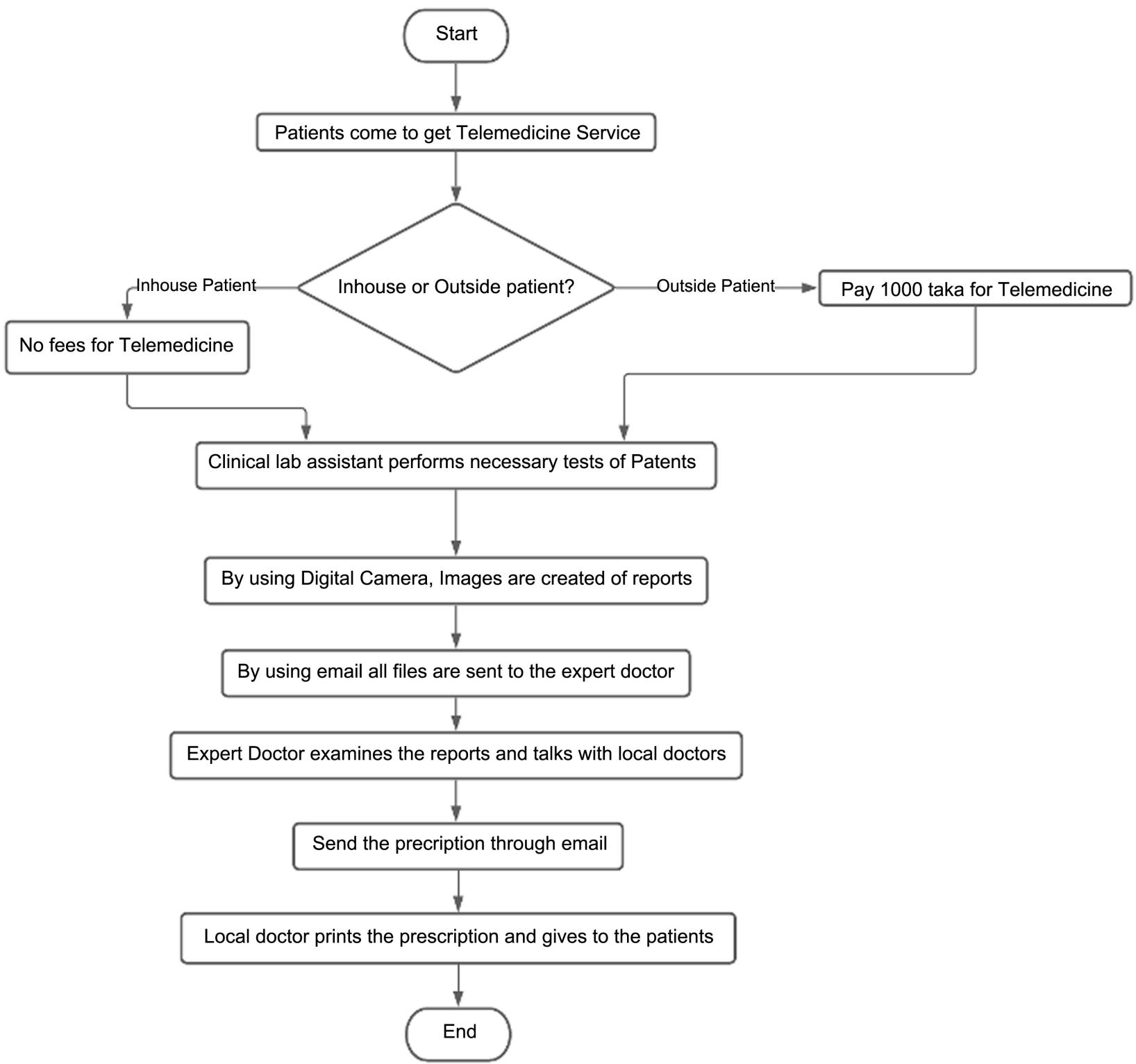

Figure 12. Flowchart of CRP telemedicine service in the earlier days.

\section{The Challenges of This System}

Specialist organization in the Government area in Bangladesh has excellent information on telemedicine applications. Be that as it may, administration beneficiaries are not notable with telemedicine. So, their observation about telemedicine isn't in fair condition. Patients not relying on telemedicine for sharing persistent data will contrarily impact the will to embrace and utilize telemedicine. Most of the individuals in Bangladesh are unconscious about the use of telemedicine. Just a fraction of the population is aware of telemedicine, which is a great challenge to deal with in a time of need [24]. Other challenges include the limitation of technical resources that are available. It is an issue for an underdeveloped country to get all the technical resources for the seamless service. The patient's acceptance rate is also an issue as most of the people are habituated with 


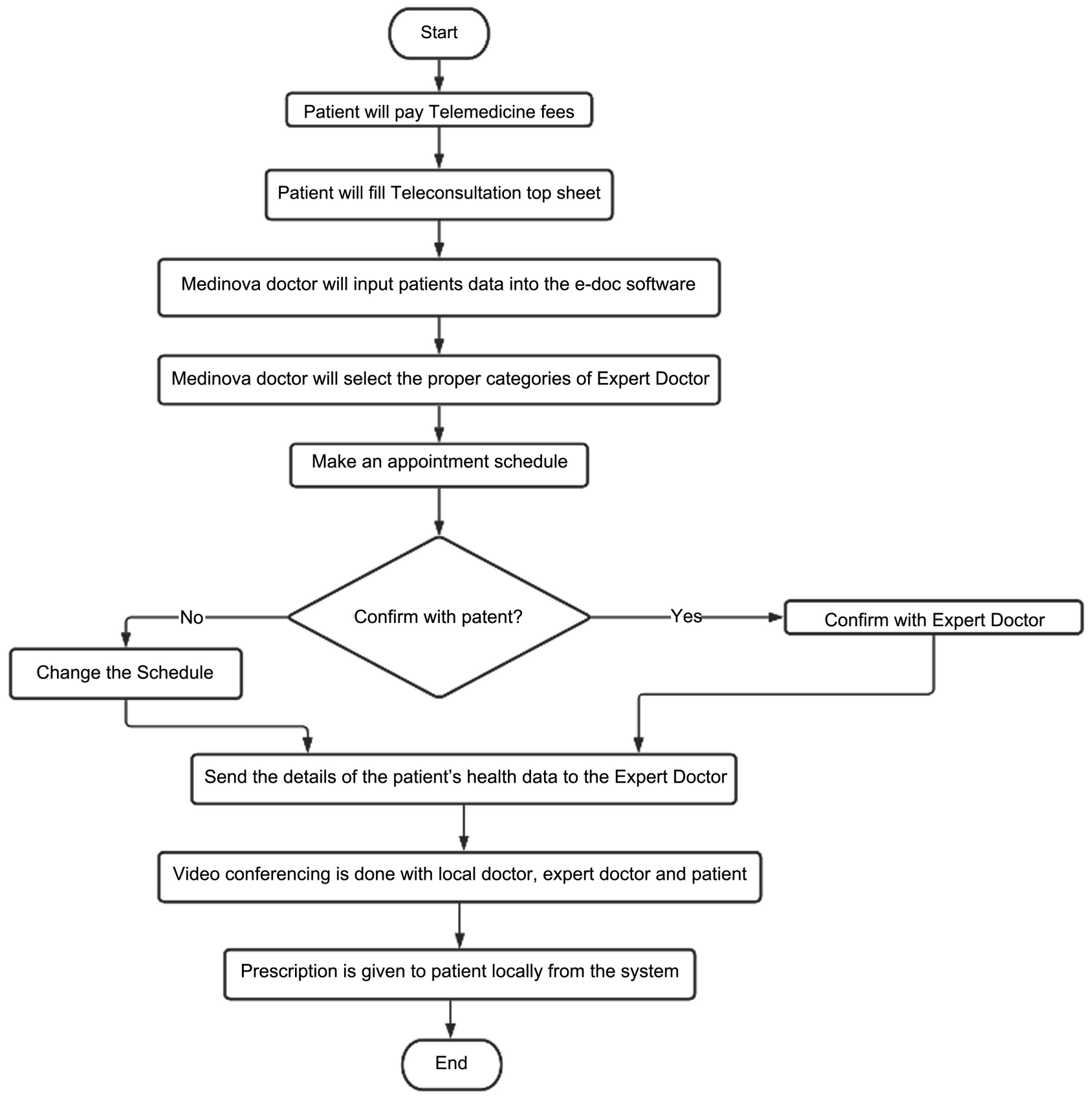

Figure13. Flowchart of telemedicine service in Medinova hospital.

the traditional way of seeing a doctor and as most of the people are in rural areas, they lack the interest in adopting the new technology that is required. As telemedicine is a new concept, it will require more advertisement to reach more people and lack of proper marketing is also a challenge. It is seen that most people are not comfortable with the new system and have trust issues regarding the quality of the service. As most of the telemedicine companies are startups, will face the challenge of fund to run the company along with the challenge of an expert team that will be required to run the company. As most of the target customers will be from rural areas, the employees of the companies will feel less 
motivated to work in rural areas.

\section{The Importance of Telemedicine during the Pandemic}

As the quick transmission of dangerous COVID has expanded fear among individuals amid the pandemic emergency and it has gotten more hazardous for a wide range of patients, including the COVID-19 ones to go to a specialist or medical clinic for taking therapy, telemedicine administrations have shown up as an answer. Because of the profoundly infectious nature of the virus, it has made frenzy among the specialists, medical caretakers and patients the same. In Bangladesh, after its outbreak, not only the patients but also several doctors, along with nurses, became the victim of COVID-19 and died from it.

In these conditions, the requirement for the advanced arrangement of medical care benefits, that is, Telehealth, telemedicine and video conference with patients, has become basic now like never before. It is a way to deal with, overcome any barrier between the patients and specialists in two different geographic areas and to empower robust clinical consideration [25].

\section{Barriers to the Use of Telemedicine}

Outside of crucial situations, the whole takes up of Telehealth has been steady and shattered. 14 to 15 substantial attempts have gone into stepping-up the routine apply of Telehealth, often with small amount of success. In Australia, in spite of the introduction of liberal financial inducement for specialist video negotiations, Telehealth constituted less than $1 \%$ of all expert's consultations provided [26] [27]. The scenario in the United States has been alike, where less than $2 \%$ of people living in rustic areas have ever participated in Telehealth. The causes for the low taking up of Telehealth are having many facets and diverse, but components such as clinician disposition, economic reimbursement and corporation of the health system may be to condemn [28] [29] [30]. In Bangladesh, use of telemedicine faces a number of barriers. The challenges that are hindering to provide the full advantages of telemedicine services to the people of Bangladesh are described below.

\subsection{Shortage of ICT Access}

Bangladesh has very limited ICT infrastructural support for example, Computers, Internet network, Printers, and electricity for telemedicine. According to the Bangladesh Telecommunication Regulatory Commission report of April 2020, the total number of Internetusers is 101.186 million and the total number of mobile phone subscribers is 162.920 million [31] [32]. Although the number is impressive but in reality, it varies. We need to take poor internet connection, lack of stable signal and high cost of web access into account. What's more, electricity isn't reliable here. That is why majority of the people tend to lean on traditional and relatively low-tech ICT options to have access to health-related consultancy. 


\subsection{Lack of Motivation}

Older administrative stuff in the medical sector of Bangladesh has an absence of inspiration to try out new technology. They don't need any sort of progress in their recognizable workplace. Rather, in a sub-district country clinic, doctors experience substantial outstanding tasks at hand, absence of viable working environment, incompatible financial and expert benefits, and less assignment of sufficient assets for achieving patient health expectations are the reasons for this lack of motivation.

\subsection{Lack of Knowledge Regarding Telemedicine}

The general proficiency rate is $73.91 \%$ in Bangladesh among grown-ups ages 15 years and above. Health education is "the degree to which people have the ability to acquire, measure, and comprehend essential wellbeing data and administrations expected to settle on fitting wellbeing choices". Conversely, telemedicine or computerized wellbeing education expands this definition to incorporate the capacity to assess wellbeing data from electronic sources and apply the information picked up to address or take care of a medical condition. Proper information about wellbeing proficiency are not accessible; be that as it may, a study led in 2017 found that $7 \%$ of respondents had poor, $49 \%$ had poor and $41 \%$ had reasonable oral wellbeing education level [33] [34]. Restricted wellbeing and advanced wellbeing proficiency are all around portrayed as obstructions to getting ideal clinical service.

\section{Conclusion}

While we are not being able to accurately foretell the timing of global disasters and contagious pandemics, we can't assure that they will occur again in the future. But the COVID-19 encounter is not a first, or nor will it be the last too. Telemedicine have some critical part in emergency responses. Ascending of Telemedicine incorporates the ability rapidly deploy huge numbers of donators; privileges triage in order that front-line donators are not engulfed with new demonstrations; supply analytic services when district clinics or medicals or hospitals are blemished or unable to fulfil demand; and lessen the risk of infective diseases that can be transmitted from one person to another person. Readiness is the key to convey any health difficulties, and until now, Bangladesh, as a middle-income country, has various limitations in reducing the outspread of the virus [35]. While ongoing the lockdown at any situation with more firm maintenance, the country has to extend its testing and healthcare privileges. It has to be assured of a constant reservation of PPE for healthcare nurses and workers. Most importantly, improvised and well-timed measures taken with required coordination may assist the country to struggle the lethal virus. Government won't be able to alleviate the situation alone; independent attempts from the common people, direct participation of the nation's general health specialists, and international association are urgently required. Since the situation intensifies, the universe is 
closely observing how Bangladesh will manage this crisis. Now second wave of COVID-19 has already been started. More people are being affected by the coronavirus. It is very important to take the service of telemedicine. In this case patients can take the healthcare services staying at home. Due to the high-speed internet and good telecommunication network, it has been possible to provide Telemedicine in isolated areas where modern medical facilities are absent. Digital healthcare is a new idea and most of the people in our country are living in villages. We need to create awareness of these people about health. This system will be a blessing in future for the people of the whole world. It will save the life expectancy of the whole world.

\section{Acknowledgements}

Authors would like to thank Department of Electrical and Computer Engineering at North South University, Bangladesh.

\section{Conflicts of Interest}

The authors declare no conflict of interest.

\section{References}

[1] World Health Organization (2020) WHO Director-General's Opening Remarks at the Media Briefing on COVID-19 11 March 2020.

https://www.who.int/director-general/speeches/detail/who-director-general-s-openi ng-remarks-at-the-media-briefing-on-covid-19---11-march-2020

[2] Public Health England (2020) Coronavirus (COVID-19): What Is Social Distancing?

https://publichealthmatters.blog.gov.uk/2020/03/04/coronavirus-covid-19-what-is-s ocial-distancing/

[3] Priya, S. (2020) Singapore Government Launches COVID-19 Chatbot. https://www.opengovasia.com/singapore-government-launches-covid-19-chatbot/

[4] Suneela, G. and Navya, G. (2020) Official Publication of the Academy of Family Physicians of India. Journal of Family Medicine and Primary Care, 9, 2-6.

[5] Hong, Z., Li, N., Li, D., Li, J., Li, B., Xiong, W., Li, W.-M. and Zhou, D. (2020) Telemedicine during the COVID-19 Pandemic: Experiences from Western China (Preprint). Journal of Medical Internet Research, 22, e19577. https://doi.org/10.2196/19577

[6] Chowdhury, S.R., Sunna, T.C. and Ahmed, S. (2020) Telemedicine Is an Important Aspect of Healthcare Services Amid COVID-19 Outbreak: Its Barriers in Bangladesh and Strategies to Overcome. The International Journal of Health Planning and Management, 36, 4-12. https://doi.org/10.1002/hpm.3064

[7] Smith, A.C. and Gray, L.C. (2009) Telemedicine across the Ages. The Medical Journal of Australia, 190, 15-19.

[8] Rosenbaum, E. (2020) Robotic Medicine May Be the Weapon the World Needs to Combat the Coronavirus.

https://www.cnbc.com/2020/02/26/robotic-medicine-may-be-the-weapon-needed-t o-combat-the-coronavirus.html/

[9] Doarn, C.R., Latifi, R., Poropatich, R.K., Sokolovich, N., Kosiak, D., Hostiuc, F., et 
al. (2018) Development and Validation of Telemedicine for Disaster Response: The North Atlantic Treaty Organization Multinational System. Telemedicine and e-Health, 24, 657-668. https://doi.org/10.1089/tmj.2017.0237

[10] Doarn, C.R., Latifi, R., Hostiuc, F., et al. (2017) A Multinational Telemedicine System for Disaster Response: Opportunities and Challenges. IOS Press, Amsterdam.

[11] Wicklund, E. (2017) Harvey's Aftermath Brings mHealth, Telehealth to the Forefront.

https://mhealthintelligence.com/news/harveys-aftermath-brings-mhealth-telehealth -to-the-forefront

[12] BANBEIS (2011) Bangladesh Bureau of Educational Information \& Statistics Report. Ministry of Education, Bangladesh.

[13] Directorate General of Health Services (n.d.) Telemedicine Service. http://www.dghs.gov.bd/index.php/en/component/content/article/84-english-root/e health-eservice/490-telemedicine-service

[14] Pulse Health Services Limited (n.d.). https://pulsehealthbd.com/

[15] Jeeo Connect (n.d.). https://www.jeeon.co/jeeonconnect/

[16] Sebaghar.com (n.d.). https://sebaghar.com/registration/appointment

[17] Bachao-Health (n.d.). https://www.facebook.com/bachaohealth/

[18] Tonic (n.d.). https://www.mytonic.com/

[19] World Health Organization (2020) WHO Bangladesh COVID-19 Situation Reports. https://www.who.int/bangladesh/emergencies/coronavirus-disease-(covid-19)-upda te/coronavirus-disease-(covid-2019)-bangladesh-situation-reports/

[20] Worldometer (2020) COVID-19 Coronavirus Pandemic. https://www.worldometers.info/coronavirus/

[21] Dhaka Tribune (2020) Coronavirus: Doctors' Mortality Rate in Bangladesh "Highest in the World".

https://www.dhakatribune.com/health/coronavirus/2020/06/20/coronavirus-doctors -mortality-rate-in-bangladesh-highest-in-the-world

[22] CRP (2013) Annual Report 2013-2014.

http://www.crp-bangladesh.org/index.php?option=com_joomdoc\&task=cat_view\& gid=41\&Itemid $=65$

[23] Sanaullah Chowdhury, M., Kabir, M.H., Ashrafuzzaman, K. and Kwak, K.-S. (2009) A Telecommunication Network Architecture for Telemedicine in Bangladesh and Its Applicability. International Journal of Digital Contents Technology and Its Applications, 3, 156-166.

[24] Zhao, J., Zhang, Z., Guo, H., Li, Y., Xue, W., Ren, L., Chen, Y., et al. (2010) E-Health in China: Challenges, Initial Directions, and Experience. Telemed E-Health, 16, 344-349. https://doi.org/10.1089/tmj.2009.0076

[25] Caffery, L.J. (2016) Telehealth Interventions for Reducing Waiting Lists and Waiting Times for Specialist Outpatient Services: A Scoping Review. Journal of Telemedicine and Telecare, 22, 504-512. https://doi.org/10.1177/1357633X16670495

[26] Department of Health (2020) Amended MBS Mental Health and Wellbeing Telehealth Items.

[27] Caffery, L.J., Meiklejohn, J., Bradford, N. and Langbecker, D. (2018) How Telehealth Facilitates the Provision of Culturally Appropriate Healthcare for Indigenous Australians. Journal of Telemedicine and Telecare, 24, 676-682. https://doi.org/10.1177/1357633X18795764

[28] Bradford, N.K., Caffery, L.J. and Smith, A.C. (2016) Telehealth Services in Rural 
and Remote Australia: A Systematic Review of Models of Care and Factors Influencing Success and Sustainability. Rural Remote Health, 16, Article No. 3808.

[29] Peddle, K. (2007) Telehealth in Context: Socio-Technical Barriers to Telehealth Use in Labrador, Canada. Computer Supported Cooperative Work, 16, 595-614. https://doi.org/10.1007/s10606-006-9030-3

[30] Wade, V., Soar, J. and Gray, L. (2014) Uptake of Telehealth Services Funded by Medicare in Australia. Australian Health Review, 38, 528-532. https://doi.org/10.1071/AH14090

[31] Bangladesh Telecommunication Regulatory Commission (2020) Mobile Phone Subscribers in Bangladesh April, 2020.

http://www.btrc.gov.bd/content/mobile-phone-subscribers-bangladesh-april-2020

[32] Bangladesh Telecommunication Regulatory Commission (2020) Internet Subscribers in Bangladesh April, 2020.

http://www.btrc.gov.bd/content/internet-subscribers-bangladesh-april-2020

[33] Norman, C.D. and Skinner, H.A. (2006) eHealth Literacy: Essential Skills for Consumer Health in a Networked World. Journal of Medical Internet Research, 8, e9. https://doi.org/10.2196/jmir.8.2.e9

[34] Mahmud, S.Z., Amin, M.S., Tarafder, M.A. and Hossain, S.M. (2017) Measurement of Oral Health Literacy Level among Bangladeshi Adults Seeking Dental Care and Its Relationship with Socio-Demographic Characteristics. Anwer Khan Modern Medical College Journal, 7, 34-39. https://doi.org/10.3329/akmmcj.v7i1.31611

[35] Wade, V.A., Eliott, J.A. and Hiller, J.E. (2014) Clinician Acceptance Is the Key Factor for Sustainable Telehealth Services. Qualitative Health Research, 24, 682-694. https://doi.org/10.1177/1049732314528809 